Article

\title{
The Genome Analysis of Methylobacterium populi YC-XJ1 with Diverse Xenobiotics Biodegrading Capacity and Degradation Characteristics of Related Hydrolase
}

\author{
Xianjun Li ${ }^{1}$, Junhuan Wang ${ }^{1}$, Yang Jia ${ }^{1}$, Aikebaier Reheman ${ }^{2, *}$ and Yanchun Yan ${ }^{1, *}$ (D) \\ 1 Graduate School, Chinese Academy of Agricultural Sciences, Beijing 100081, China; \\ lixianjun1978@126.com (X.L.); wangjunhuan@caas.cn (J.W.); jia_yang@outlook.com (Y.J.) \\ 2 Key Laboratory of Toxicology, Ningde Normal University, Ningde 352100, China \\ * Correspondence: akbarphd@126.com (A.R.); yanyanchun@caas.cn (Y.Y.); Tel.: +86-10-82109685 (Y.Y.)
}

Received: 19 May 2020; Accepted: 17 June 2020; Published: 22 June 2020

check for updates

\begin{abstract}
Methylobacterium populi YC-XJ1 isolated from desert soil exhibited a diverse degrading ability towards aromatic oxyphenoxypropionic acid esters (AOPPs) herbicide, phthalate esters (PAEs), organophosphorus flame retardants (OPFRs), chlorpyrifos and phoxim. The genome of YC-XJ1 was sequenced and analyzed systematically. YC-XJ1 contained a large number of exogenous compounds degradation pathways and hydrolase resources. The quizalofop-p-ethyl (QPE) degrading gene qpeh2 and diethyl phthalate (DEP) degrading gene deph1 were cloned and expressed. The characteristics of corresponding hydrolases were investigated. The specific activity of recombinant QPEH2 was $0.1 \pm 0.02 \mathrm{U} \mathrm{mg}^{-1}$ for QPE with $k_{\text {cat }} / K_{\mathrm{m}}$ values of $1.8 \pm 0.016\left(\mathrm{mM}^{-1} \cdot \mathrm{s}^{-1}\right)$. The specific activity of recombinant DEPH1 was $0.1 \pm 0.02 \mathrm{U} \mathrm{mg}^{-1}$ for DEP with $k_{\text {cat }} / K_{\mathrm{m}}$ values of $0.8 \pm 0.02\left(\mathrm{mM}^{-1} \cdot \mathrm{s}^{-1}\right)$. This work systematically illuminated the metabolic versatility of strain YC-XJ1 via the combination of genomics analysis and laboratory experiments. These results suggested that strain YC-XJ1 with diverse xenobiotics biodegrading capacity was a promising candidate for the bioremediation of polluted sites.
\end{abstract}

Keywords: Methylobacterium populi; genome sequencing; hydrolase; quizalofop-p-ethyl; diethyl phthalate; degradation

\section{Introduction}

Quizalofop-p-ethyl (QPE), a unitary R configuration aromatic oxyphenoxypropionic acid esters (AOPPs) herbicide, was predicted to rapidly increase in coming years in an effort to overcome the widespread appearance of glyphosate-resistant weeds [1]. Due to the widespread use of QPE, some detrimental effects had been reported, such as: causing liver injury of human [2]; causing alterations of gene expression in fatty acid degradation pathways of the HepaRG cell line [1]; endocrine-disrupting and acute toxicity to zebrafish [3]; phytotoxicity to Lemna minor [4]; toxicity to soil microorganisms [5]. According to the World Health Organization (WHO) definitions of adverse drug reactions and U.S. Environmental Protection Agency (EPA) toxicity class III, QPE was toxic chemicals, already prohibited by the European Union.

Phthalate esters (PAEs) are one of the most frequently detected persistent organic pollutants in the environment [6]. Diethyl phthalate (DEP) belongs to the family of PAEs, which are the most commonly used plasticizer in China [7]. An investigation on particulate and gas-phase distribution of PAEs in Nanjing (China), approximately 75 to $89.2 \%$ of phthalate esters were present in the atmosphere in vapor form, DEP is $3.4 \mathrm{ng} \mathrm{m}^{-3}$ [8]. An analysis of gas-particle partitioning shown the vapor phase 
distribution of DEP in the atmosphere of Paris in France is 93.8\% [9]. DEP concentration is $406 \mathrm{pg} \mathrm{cm}^{-3}$ in gas-phase in the arctic which is the largest concentration of among 6 tested PAEs [10]. Due to the widespread use of DEP in personal care products, plastics and medical devices, some detrimental effects had been reported, such as chronic toxicity in male wistar rats [11]; hepatotoxicity to 21-day-old male and female weanling pups of Wistar rats [12]; causing changes of certain liver and muscle enzyme activity to freshwater fish Cirrhina mrigala [13]; causing severe impairment of lipid metabolism coupled with toxic injury of the liver in young male Sprague-Dawley rats [14]; causing neurotoxicity in zebrafish embryos [15].

Triphenyl phosphate (TPhP), as an aryl organophosphorus flame retardants (aryl-OPFRs), was extensively used in a variety of industries, such as plastics, furniture, textile, electronics, construction, vehicle and petroleum [16]. Due to its chemical properties, OPFRs were not chemically bonded to the final products, which resulted in an easy release to the environment [17], such as indoor dust [18], drinking water [19], rivers [20]. Some toxicological effects of TPhP had been reported, such as reproductive and developmental toxicity of zebrafish [21], inducing oxidative stress and endocrine disruption in mice [22].

Remediation of polluted sites using a microbial process has been proven effective and reliable due to its eco-friendly features [23]. Therefore, a series of microorganisms with degradation capacity have been isolated in recent years. Some strains from Pseudomonas sp. [24], Aquamicrobium sp. [25], Acinetobacter sp. [26] and Rhodococcus sp. [27] were identified to degrade QPE. Some strains from Acinetobacter sp. [28], Sphingomonas sp. [29], Paenibacillus sp. [30] and Ochrobactrum sp. [31] were identified to degrade DEP. Some strains from Brevibacillus brevis [32], Sphingobium sp., Sphingomonas sp. [33], Roseobacter sp. [34], Rhodococcus sp. and Sphingopyxis sp. [35] were identified to degrade TPhP. However, most of these isolates have a single function and can only degrade one kind of organic pollutants. In this research, we report the Methylobacterium populi YC-XJ1 with diverse degrading function isolated from desert soil. The whole genome was sequenced and analyzed systematically. Characteristics of related hydrolase were further investigated.

\section{Results}

\subsection{Substrates Utilization Test}

One After $72 \mathrm{~h}$ incubation, aromatic compounds including benzene, phenol, pyrocatechol, salicylic acid, benzoic acid, phthalic acid, 4-chlorobenzoic acid and haloxyfop-p-methyl, diclofop-methyl, fluazifop-p-butyl were completely degraded (100\%), as shown in Figure 1A. The AOPPs including quizalofop-p-ethyl and clodinafop-propargyl were degraded by $96.2 \%, 99.5 \%$ respectively. The PAEs including dibutyl phthalate (DBP) and DEP were degraded by $93 \%$ and $23 \%$ respectively. The degradation rate of $\mathrm{TPhP}$, diphenyl phosphate (DPP), tris(1,3-dichloro-2-propyl) phosphate (TDCPP) and tris(2chloroethyl) phosphate (TCEP) were 20.3\%, 6.9\%, 19.3\% and $8.4 \%$ respectively. The compounds with phosphorous ester bond including chlorpyrifos and phoxim were degraded by $27.3 \%$ and $16.9 \%$ respectively.

The characteristics on degrading $\mathrm{TPhP}$ by strain YC-XJ1 were further explored; the degradation ratio of $\mathrm{TPhP}$ in initial concentration $50 \mathrm{mg} / \mathrm{L}$ was $72 \%$ within 12 days in Figure $1 \mathrm{~B}$, the optional pH of TPhP by strain YC-XJ1 was pH8 (Figure S1). 


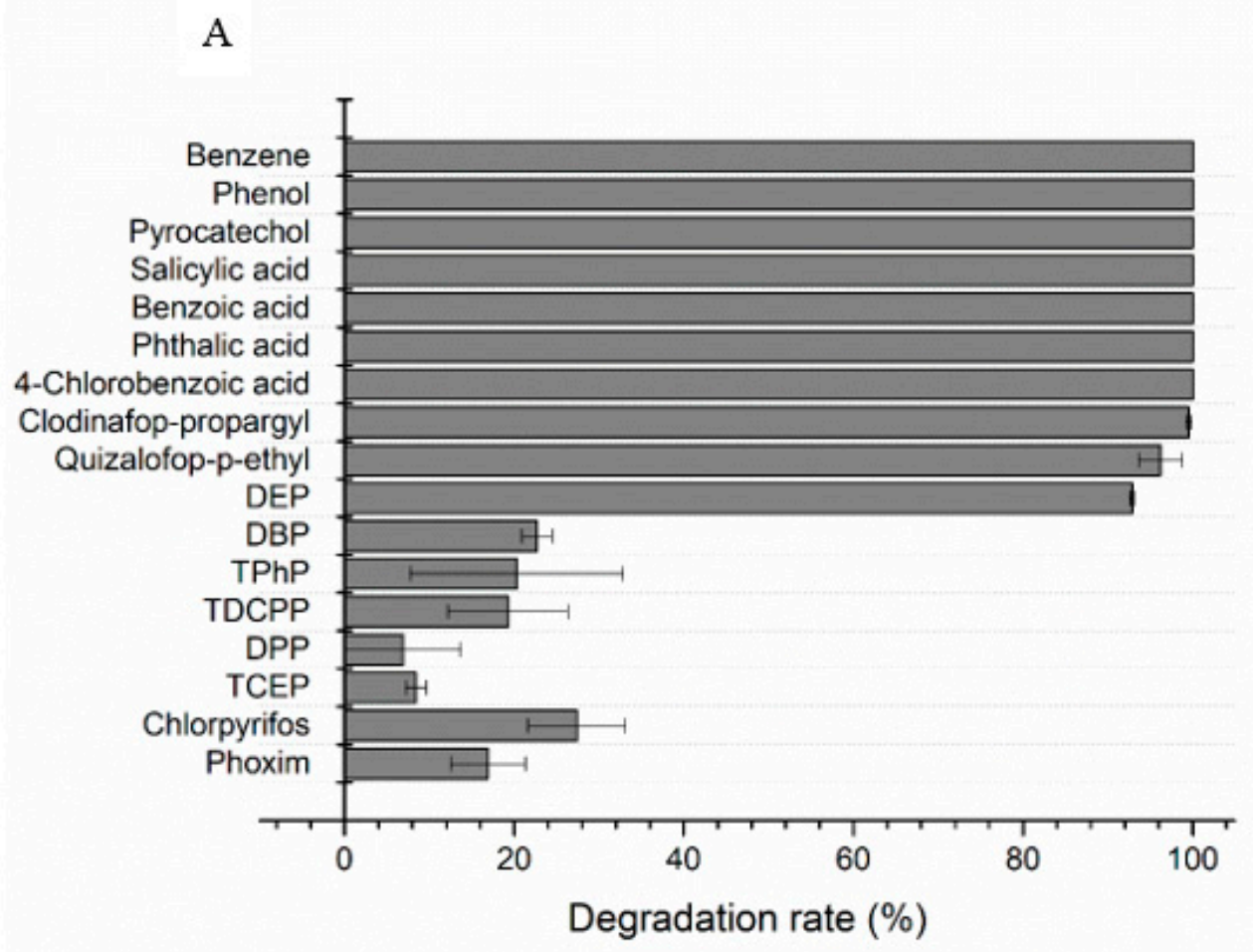

B

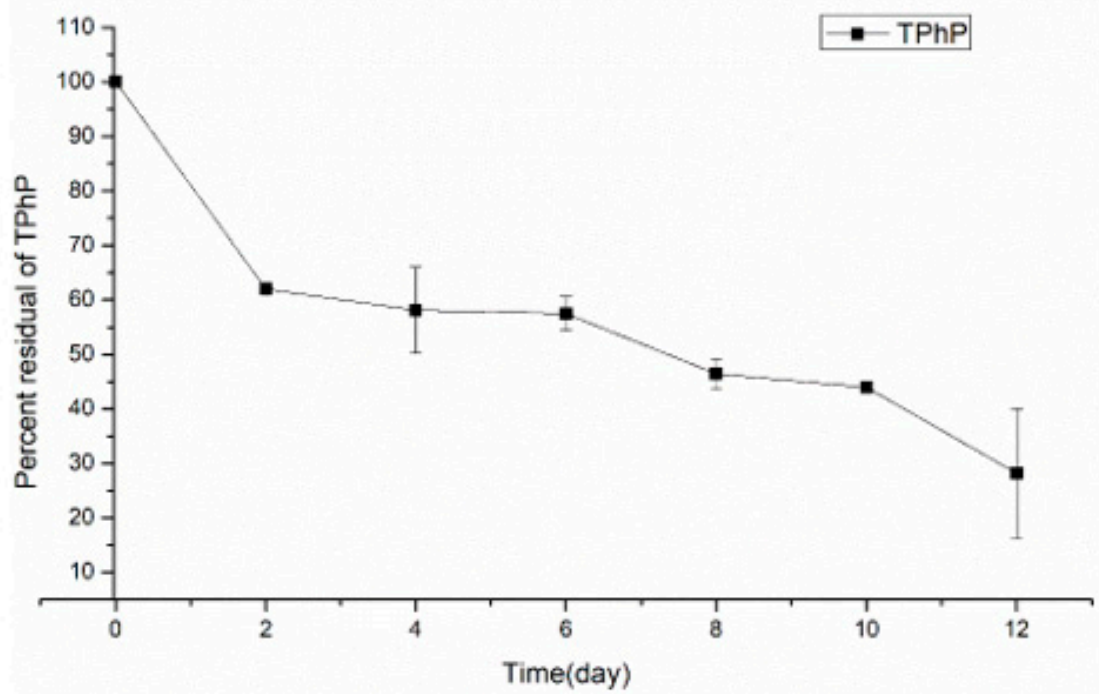

Figure 1. The degradation of various substrates by Methylobacterium populi YC-XJ1. (A) Substrate specificity of YC-XJ1; (B) Degradation of TPhP by YC-XJ1).

\subsection{Genome Properties}

The Methylobacterium populi YC-XJ1 genome was assembled into one scaffold of 5,395,646 bp with a G $+C$ content of $69.36 \%$. Gene prediction indicates a total gene length of $4,685,898 \mathrm{bp}$, with a GC content of $69.95 \%$ in the gene region and $65.47 \%$ in intergenetic region. The gene length/genome ratio is $86.85 \%$. The genome contains 10 rRNA genes, 58 tRNA genes, 1 prophage (16,754 bp); 19 gene island (549,538 bp) and 5375 coding sequences (CDSs) (Figure 2). 4387 (81.6\%) CDSs have assigned predicted functions (Figure 2). Gene numbers were multiply annotated in databases as follows: 
non-redundant (NR) (3547), Swiss-Prot (3174), Cluster of Orthologous Groups of proteins (COGs) (4170), Kyoto Encyclopedia of Genes and Genomes (KEGGs) (2310), Gene Ontology (GO) (3458), Pfam (3853), Carbohydrate-Active enzymes (CAZy) (166), Pathogen Host Interactions (PHI) (659), Virulence Factors Database (VFDB) (435) and Comprehensive Antibiotic Research Database (CARD) (249), as shown in Table S1.

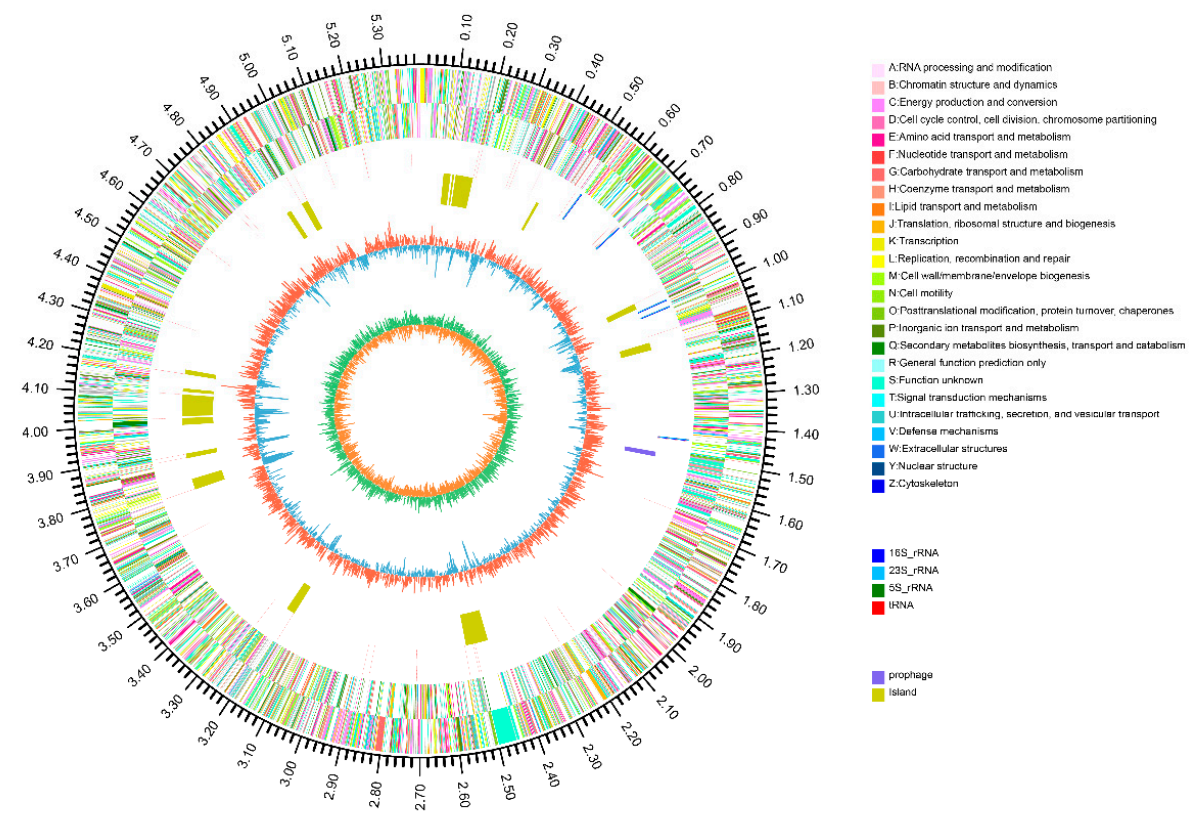

Figure 2. Schematic of the complete Methylobacterium populi YC-XJ1 genome. Circles are numbered from the outermost (first) to the innermost (eighths) circle and include the following features: the scale line, with each major tick representing $0.1 \mathrm{Mb}$ (first circle); coding DNA sequences on forward and reverse chains, with different colors based on clusters of orthologous groups of proteins (COGs) categories (second and third circles); rRNA and tRNA (fourth circle); prophage (fifth circle); gene island (sixth circle); GC content (seventh circle); GC skew (eighth circle). The circular representation was drawn using Circos 0.64 .

\subsection{ANI Analysis}

To further confirm the identification of YC-XJ1, average nucleotide identity (ANI) analysis was performed using whole-genome data between YC-XJ1 and other closely related 7 genome sequence of Methylorubrum strains which retrieved from the GenBank database.

A heatmap was constructed based on ANI values (Figure S2), the whole genome phylogenetic tree showed YC-XJ1 was closestly relative to Methylobacterium populi BJ001, and $97.9 \%$ identical to the genome of Methylobacterium populi BJ001, with $88.6 \%$ coverage of the genome.

\subsection{Collinearity Analysis}

The collinearity analysis of the YC-XJ1 genome and the closest BJ001 genome was conducted. The collinearity and non collinearity regions of the genome of strain YC-XJ1 and BJ001 were shown in Figure S3. There was not a large area of gene location transfer and gene rearrangement between YC-XJ1 and BJ001 genome.

\subsection{Gene Function Analysis}

\subsubsection{COG Categories Reveal Metabolism-Related Functions}

Since 4170 sequences were annotated to 4 COG categories and 21 COGs types. 1342 genes (32.2\%) were annotated to the metabolism of COG categories and the metabolism COG categories included 
8 COG types (Figure S4). To determine the degrading potential of Methylobacterium populi YC-XJ1, specific COGinvolved in xenobiotics metabolism were analyzed. Among the metabolism, the four most abundant COG types were the energy production and conversion ( 270 genes, $6.5 \%)$, the amino acid transport and metabolism (265 genes, $6.4 \%$ ), the inorganic ion transport and metabolism (248 genes, $5.9 \%)$, the carbohydrate transport and metabolism (175 genes, $4.2 \%)$.

With respect to the carbohydrate transport and metabolism, It concluded a series of COG0477 (major facilitator Superfamily), COG1472 (hydrolase family 3), COG2273 (hydrolase family 16), COG1554 (hydrolase family 65), COG0647 (hydrolase), COG4993 (dehydrogenase) and COG2133 (dehydrogenase) involved the degradation of xenobiotics.

COG0477 catalyzes the transport of various substrates, including carbohydrates, ions, and other small molecules. It was referred to as a secondary active transporter [36]. COG1472 (hydrolase family 3) was a beta-glucosidase or beta-hexosaminidase. COG2273 (hydrolase family 16) was a glycoside hydrolase. COG0647 (hydrolase) was a haloacid dehalogenase. COG1554 (hydrolase family 65) was a kojibiose phosphorylase. COG4993 (dehydrogenase) was a methanol dehydrogenase. COG2133 (dehydrogenase) was a glucose or sorbosone dehydrogenase. The wide diversity of gene function reveals a high potential for Methylobacterium populi YC-XJ1 in carbohydrate degradation.

Another obvious characteristic of Methylobacterium populi YC-XJ1 was that 1367 genes $(32.8 \%)$ were annotated to Function unknown, implying many proteins with degrading function have not yet to be identified (Figure S4).

\subsubsection{GO Terms Reveal Biological Relevance}

To determine the biological relevance of the Methylobacterium populi YC-XJ1 gene pool, genes were categorized by GO analysis based on matches to sequences of known functions in three categories: biological process, cellular component, and molecular function (Figure S5). GO terms of the molecular function (2733 genes) were the most abundant, followed by biological process ( 2473 genes) and cellular component (1674 genes).

For Methylobacterium populi YC-XJ1 isolated from the desert soil under higher temperature alkaline environment, genes in molecular function category fell into 12 sub-functions, with most involved in catalytic activity (GO:0003824, 2023, 48.0\%) and binding (GO:0005488, 1385, 32.9\%); genes in the biological process category fell into sixteen sub-functions, with a large proportion of genes being involved in metabolic process (GO:0008152, 1910, 27.0\%), cellular process (GO:0009987, 1558, 22.0\%), and single-organism process (GO:0044699, 1354, 19.1\%); genes in the cellular component category fell into 12 sub-functions, with most involved in functions of membrane (GO:0016020, 1092, 26.2\%), membrane part (GO:0044425,992, 23.8\%), cell (GO:0005623, 890, 21.4\%), and cell part (GO:0044464, $870,20.9 \%)$.

Based on the GO annotation of Methylobacterium populi YC-XJ1, genes in the catalytic activity, metabolic process, and cellular process sub-functions were the three most abundant.

\subsubsection{CAZy Families Reveal Carbohydrate-Active Enzyme Genes}

To further understand the carbohydrate degradation capacity of YC-XJ1, genes were annotated against the CAZy database. YC-XJ1 contained 166 gene counts distributed unequally among glycoside hydrolases (GHs; 26.51\%), carbohydrate esterases (CEs; 16.87\%), glycosyl transferases (GTs; 46.39\%), auxiliary activities (AAs; 6.02\%), and carbohydrate binding modules (CBMs; 1.20\%) (Figure S6). With the highest gene counts percent, the enzymes of the GHs, CEs and GTs families played key roles in the cleavage of substrates [37].

Carbohydrate esterases (CEs) catalyzed the de-O or de-N-acylation by removing the ester decorations from carbohydrates [38]. CEs were currently classified into 15 families in the CAZy database, and CEs had important significance as biocatalysts in a variety of bioindustrial processes and applications [39]. Among carbohydrate esterases in YC-XJ1, there were CE10 family (9 genes) associated with the degradation of AOPPs, apart from CE1 family (6 genes). CE10 family included 
carboxyl esterase (EC 3.1.1.3); arylesterase (EC 3.1.1.2); acetylcholinesterase (EC 3.1.1.7); cholinesterase (EC 3.1.1.8); sterol esterase (EC 3.1.1.13). CE1 family include carboxylesterase (EC 3.1.1.1); cinnamoyl esterase (EC 3.1.1.73); acetyl xylan esterase (EC 3.1.1.72); feruloyl esterase (EC 3.1.1.73).

The glycoside hydrolases (GH) was a well-known group of enzymes that hydrolyze the glycosidic bond of carbohydrates. GH members in YC-XJ1 included glycoside hydrolase family 15 (GH15), oxidoreductase (GH109).

\subsubsection{Analysis of Relative Metabolic Pathways}

To explore the critical metabolic pathways involved in degradation of xenobiotics by YC-XJ1, $2310(43.0 \%)$ genes were involved in 223 metabolic pathways in KEGG database. The summary of the annotated metabolic pathways was shown in Figure S7. Most genes involved in "metabolism", gene number 1438 and gene percent $62.3 \%$, more than any other categories including cellular processes, human diseases, organismal systems, genetic information processing and environmental information processing. Among metabolism, "energy metabolism" and "carbohydrate metabolism" were two primary functions of YC-XJ1 in KEGG annotations (Figure S8).

"Energy metabolism" (234, 10.1\%) represented "the plant of power" in bacterium. Methane metabolism (ko00680, 56 genes) and oxidative phosphorylation (ko00190,53) in YC-XJ1 indicated that YC-XJ1 could utilize C1 compound efficiently and released chemical energy ATP which plays a key role in carbohydrate metabolism. Carbon fixation pathways in prokaryotes $(k 000720,35)$ and carbon fixation in photosynthetic organisms $(k o 00710,18)$ implied the super capacity of carbon fixation.

"Carbohydrate metabolism" (346, 15.0\%) contained more gene number than "Energy metabolism" (234, 10.1\%). The largest gene proportion of "Carbohydrate metabolism" participated in glyoxylate and dicarboxylate metabolism (ko00630, 66).

The most important KEGG second category was "xenobiotic biodegradation and metabolism" (96, $4.2 \%)$, as shown in Table 1. Degradation pathways of single benzene ring aromatic compounds such as benzoate, styrene, toluene and xylene were annotated, and that was corresponding with the result of previous experiments. Aminobenzoate and nitrotoluene degradation pathway also were annotated, implying the strain YC-XJ1 has the function of deamination and denitrifying. Dioxin, chlorocyclohexane, chlorobenzene and fluorobenzoate halogenated aromatic compounds, atrazine and polycyclic aromatic hydrocarbon degradation pathway were annotated, explaining the dehalogenation function and the broad substrate of YC-XJ1.

Table 1. Details of genes in type of "xenobiotics biodegradation and metabolism".

\begin{tabular}{ccc}
\hline Pathway ID & Description & Gene No. \\
\hline ko00982 & Drug metabolism-cytochrome P450 & 13 \\
ko00980 & Metabolism of xenobiotics by cytochrome P450 & 12 \\
ko00791 & Atrazine degradation & 10 \\
ko00362 & Benzoate degradation & 8 \\
ko00930 & Caprolactam degradation & 8 \\
ko00627 & Aminobenzoate degradation & 8 \\
ko00625 & Chloroalkane and chloroalkene degradation & 7 \\
ko00643 & Styrene degradation & 7 \\
ko00983 & Drug metabolism-other enzymes & 7 \\
ko00361 & Chlorocyclohexane and chlorobenzene degradation & 4 \\
ko00633 & Nitrotoluene degradation & 3 \\
ko00621 & Dioxin degradation & 2 \\
ko00626 & Naphthalene degradation & 2 \\
ko00622 & Xylene degradation & 2 \\
ko00364 & Fluorobenzoate degradation & 1 \\
ko00624 & Polycyclic aromatic hydrocarbon degradation & 1 \\
ko00623 & Toluene degradation & 1 \\
\hline
\end{tabular}




\subsection{Characteristics of QPEH2 Hydrolase}

One gene was selected according to the annotation results, and named as qpeh2. The cloned qpeh2 gene was $1104 \mathrm{bp}$ in length with a GC content of $72.7 \%$ and encoded a protein of 367 amino acids with a calculated molecular mass of 39,840 Da. No signal peptide in protein sequence. The alignment analysis results showed QPEH2 contained the conserved esterase family sequence motif (G-X-S-X-G) and the catalytic triad (Ser-Asp-His) in Figure 3. This suggested that QPEH2 was a member of esterase family.
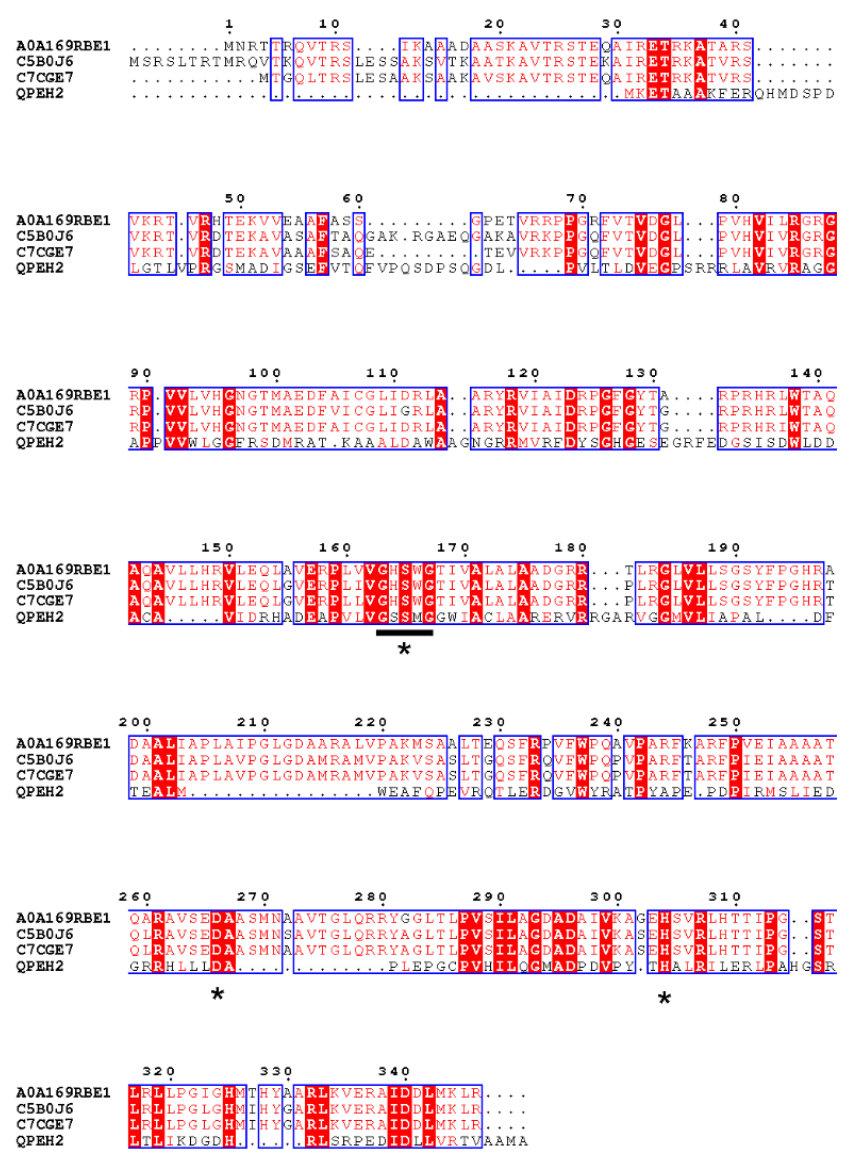

Figure 3. The sequence alignment of QPEH 2 with the most closely related proteins. (A0A169RBE1, $\alpha / \beta$ hydrolase of Methylorubrum populi, available in UniProt Knowledgebase; C5B0J6, Putative hydrolase of Methylorubrum extorquens ATCC 14718; C7CGE7, Putative hydrolase of Methylorubrum extorquens DSM 6343, available in the UniProt Knowledgebase. The conserved hydrolase motif (G-X-S-X-G) was underlined, and the amino acids that form the catalytic triad (Ser-Asp-His) was indicated by asterisks.

The identical amino acid residues were shown in red color).

Members of subfamilies I-VIII and all esterases of QPE-degrading reported were used to construct a phylogenetic tree to verify the evolutionary relationship between QPEH2 and other esterases. Most of the 8 esterases of QPE-degrading reported were included in family V and VIII (Figure 4). The QPEH2 belonged to family V. The QPEH2 shared $25.7 \%$ identity with QpeH which is the most closely related QPE-degrading hydrolase from Pseudomonas sp. J-5. This result revealed significant differences of QPEH2 with other QPE-degrading hydrolases.

Purification was analyzed by SDS-PAGE and the result showed that an approximate $45 \mathrm{kDa}$ protein was obtained. The recombinant QPEH2 most likely corresponded to the $5 \mathrm{kDa}$ of His-Tag/S.Tag sequences fused to the expected $40 \mathrm{kDa}$ qpeh2 gene product (Figure 5). 


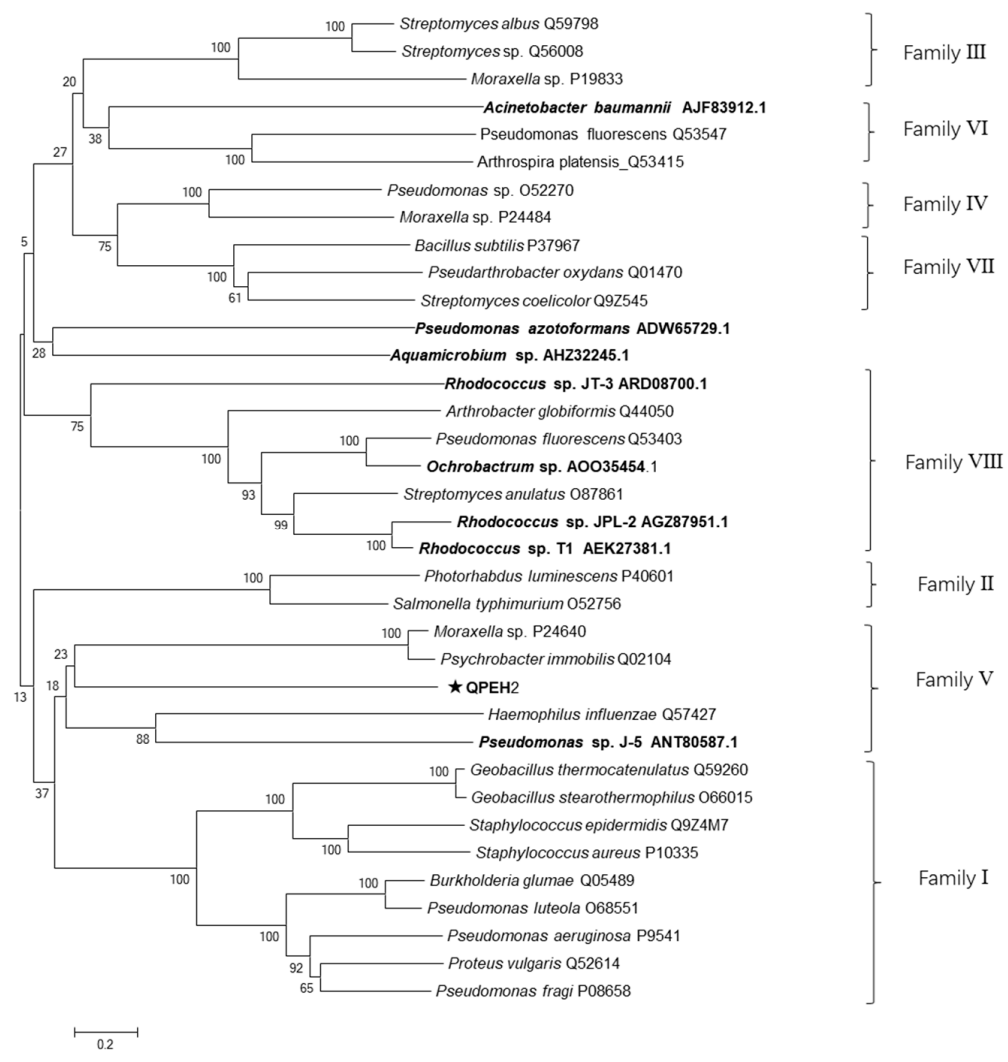

Figure 4. The phylogenetic analysis of QPEH2. The phylogenetic tree was constructed using Mega 5.0 by the neighbor-joining method, bootstrapping of 1000 replicates and Poisson model, and the details of sequences were showed in Table S2. The bold-type letters represent all the QPE-degrading esterases reported.

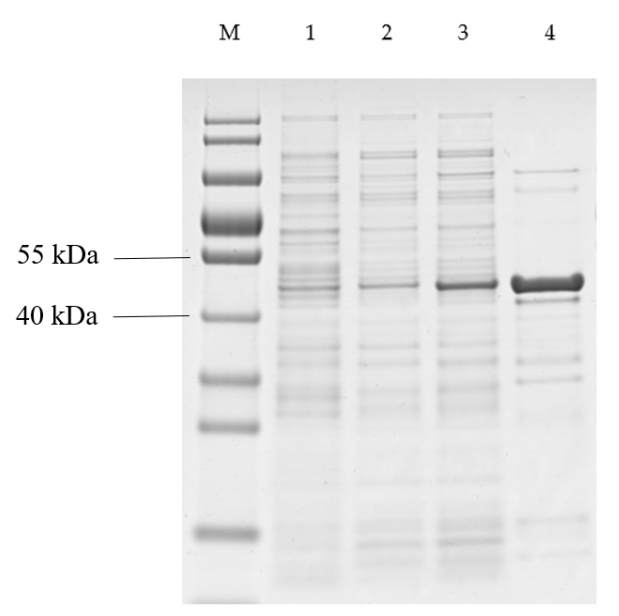

Figure 5. SDS-PAGE analysis of QPEH2 purification. Lane M: protein marker; lane 1: total protein of E. coli (pET32a); lane 2: total protein of E. coli (pET32a-qpeh2) without induction; lane 3: total protein of E. coli (pET32a-qpeh2) after induction with IPTG; lane 4: purified recombinant QPEH2.

The recombinant QPEH2 exhibited high levels of activity at $\mathrm{pH7}-10$, with an optimum $\mathrm{pH}$ of 8.0 (Figure 6A). The enzyme was active at $20-45^{\circ} \mathrm{C}$, with an optimum temperature of $30{ }^{\circ} \mathrm{C}$ (Figure 6B).

Most of the metal ions decreased enzymatic activity of $\mathrm{QPEH} 2$, especially, the $\mathrm{Cd}^{2+}, \mathrm{Pb}^{2+}, \mathrm{Zn}^{2+}$, $\mathrm{Ni}^{2+}, \mathrm{Co}^{2+}, \mathrm{Fe}^{3+}$ has a significant inhibitory effect (Figure 6C), only $\mathrm{Fe}^{2+}$ increased enzymatic activity at a concentration of $1 \mathrm{mM}$. 
The substrate specificity of QPEH2 was assessed with various AOPPs (Figure 6D). The catalytic efficiency of QPEH2 toward different AOPPs herbicides in descending order was as follows: clodinafop-propargyl $>$ diclofop-methyl $>$ haloxyfop-p-methyl $>$ fluazifop-p-butyl $>$ cyhalofop-butyl $>$ fenoxaprop-p-ethyl $>$ QPE $>$ propaquizafop $>$ quizalofop-p-tefuryl.

The specific activity of recombinant QPEH2 was $0.1 \pm 0.02\left(\mathrm{U} \mathrm{mg}^{-1}\right)$ for QPE with $k_{\text {cat }} / K_{\mathrm{m}}$ and $V_{\max }$ value of $1.8 \pm 0.016\left(\mathrm{mM}^{-1} \cdot \mathrm{s}^{-1}\right)$ and $0.38 \pm 0.14\left(\mu \mathrm{M} \cdot \mathrm{s}^{-1}\right), K_{\mathrm{m}}$ of $83.87 \pm 30.34 \mu \mathrm{M}$.

In addition, the metabolites of QPE were identified by HPLC-MS analysis. Two metabolites of quizalofop-p (QP) and (4-(6-Chloroquinoxalin-2-yloxy) phenol (CYP) were detected (Figure 6E). Proposed pathway of QPE hydrolysis by QPEH2 (Figure 6F).
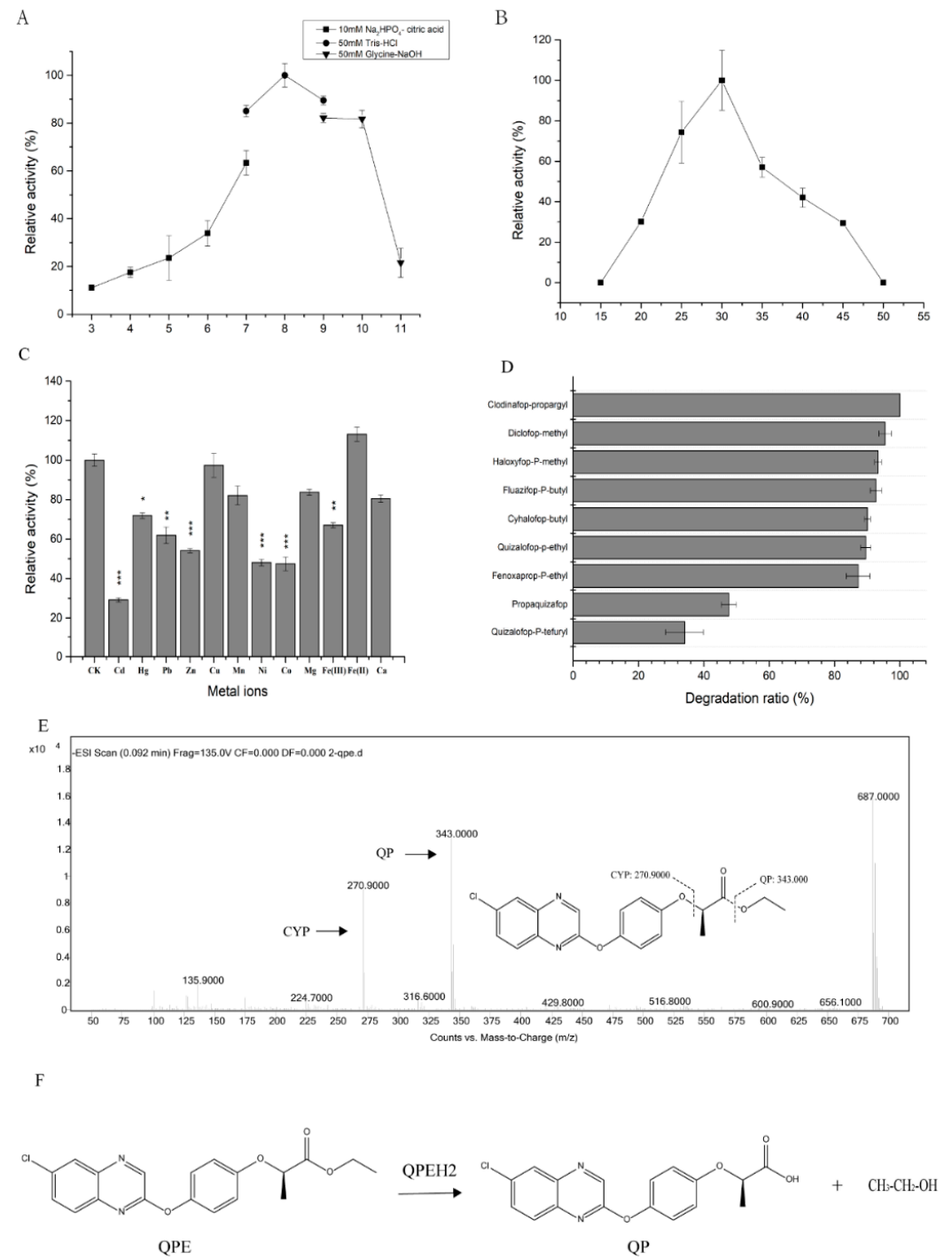

Figure 6. Characteristics of the hydrolase QPEH2. (A) $\mathrm{pH}$; (B) temperature; (C) metal ions; (D) substrate specificity of QPEH2; (E) the HPLC-MS analysis of intermediates of QPE degradation by QPEH2; (F) the metabolic pathway of QPE by QPEH2; the asterisks $\left.{ }^{* * *}\right)$ represent significant differences $(p \leq 0.001)$; the asterisks ${ }^{* *}$ ) represent significant differences $(p \leq 0.01)$; the asterisks $\left(^{*}\right)$ represent significant differences $(p \leq 0.05)$.

\subsection{Enzymatic Characteristics of DEPH1}

One gene was selected according to the annotation results, and named as deph1. The cloned deph1 gene was $843 \mathrm{bp}$ in length with a GC content of $72.7 \%$ and encoded a protein of 280 amino acids with a calculated molecular mass of $29,714 \mathrm{Da}$. No signal peptide in protein sequence. The alignment 
analysis results showed DEPH1 contained the conserved esterase family sequence motif (G-X-S-X-G) and the catalytic triad (Ser-Asp-His) in Figure S9. This suggested that DEPH1 was a member of esterase family. Members of subfamilies I-VIII and DEPH1 were used to construct a phylogenetic tree to verify the evolutionary relationship between DEPH1 and other esterases. The DEPH1 belonged to Family VII (Figure S10). The DEPH1 shared 28.6\% identity with P37967 which is the most closely related carboxylic ester hydrolase from Bacillus subtilis. This result revealed significant differences of DEPH1 with other hydrolases reported.

Purification was analyzed by SDS-PAGE and the result showed that an approximate $48 \mathrm{kDa}$ protein was obtained. The recombinant DEPH1 most likely corresponded to the $18 \mathrm{kDa}$ of Trx.Tag/His·Tag/S.Tag sequences fused to the expected $30 \mathrm{kDa}$ deph1 gene product (Figure S11).

The recombinant DEPH1 exhibited high levels of activity toward DEP at $\mathrm{pH} 4-8$, with an optimum $\mathrm{pH} 6.0$ (Figure 7A). The enzyme was active at $20-35^{\circ} \mathrm{C}$, with an optimum temperature of $35^{\circ} \mathrm{C}$ (Figure 7B).

Most of the metal ions decreased enzymatic activity of DEPH1 toward DEP, such as $\mathrm{Cd}^{2+}, \mathrm{Pb}^{2+}$, $\mathrm{Zn}^{2+}, \mathrm{Ni}^{2+}, \mathrm{Co}^{2+}$ and $\mathrm{Mn}^{2+}$. Only $\mathrm{Mg}^{2+}$ and $\mathrm{Fe}^{3+}$ increased enzymatic activity (Figure $7 \mathrm{C}$ ).

The substrate specificity of DEPH1 was assessed with 4 PAEs (Figure 7D). The catalytic efficiency of DEPH1 toward different PAEs in descending order was as follows: DMP $>$ DEP $>$ DBP $>$ DOP (Figure 7D).

The specific activity of recombinant DEPH1 was $0.1 \pm 0.04\left(\mathrm{U} \mathrm{mg}^{-1}\right)$ for DEP with $k_{\text {cat }} / K_{\mathrm{m}}$ and $V_{\max }$ value of $0.8 \pm 0.02\left(\mathrm{mM}^{-1} \cdot \mathrm{s}^{-1}\right)$ and $0.23 \pm 0.05\left(\mu \mathrm{M} \cdot \mathrm{s}^{-1}\right), K_{\mathrm{m}}$ of $1.04 \pm 0.27 \mathrm{mM}$.

A

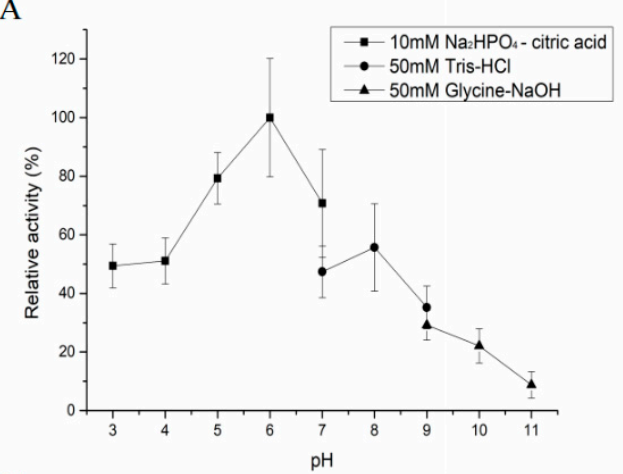

c

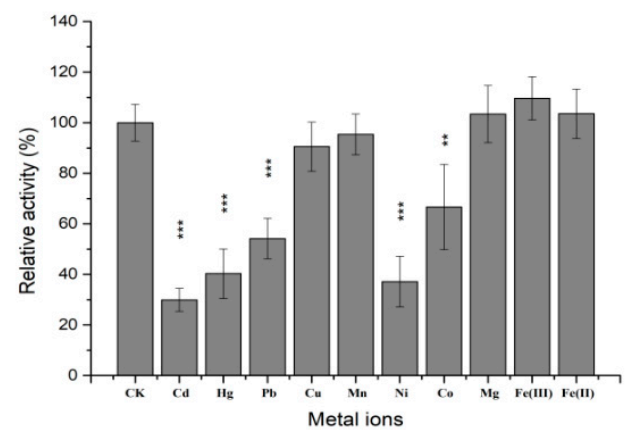

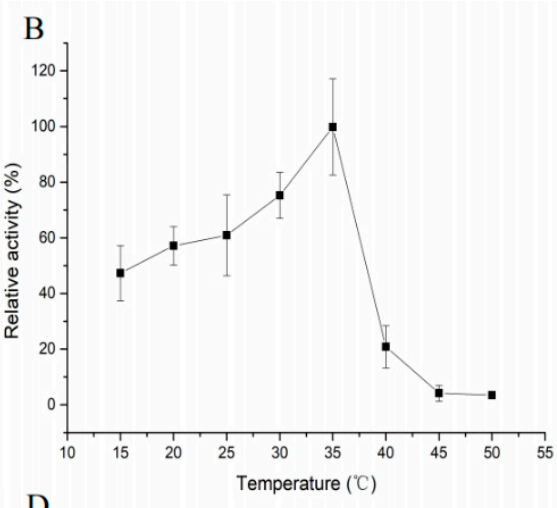

$\mathrm{D}$

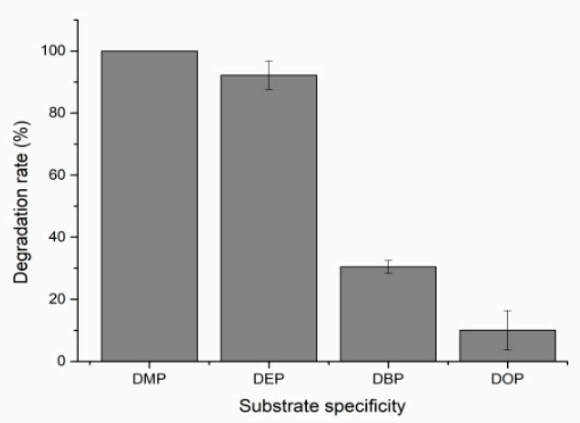

Figure 7. Characteristics of the hydrolase DEPH1. (A) $\mathrm{pH}$; (B) temperature; (C) metal ions; (D) substrate specificity of DEPH1; the asterisks $\left(^{* * *}\right)$ represent significant differences $(p \leq 0.001)$; the asterisks $\left.{ }^{* *}\right)$ represent significant differences $(p \leq 0.01)$.

\section{Discussion}

According to the results of substrates utilization test, YC-XJ1 showed the ability to degrade a variety of different types of organic pollutants, such as QPE (AOPPs herbicide), DEP (PAEs), TPhP (OPFRs) chlorpyrifos and phoxim (organophosphate insecticides). Based on the reports, Acinetobacter sp. 
DL-2 could degrade $90.1 \%$ of QPE (50 mg/L) within 120 h [26], Aquamicrobium sp. FPB-1 could degrade $98.5 \%$ of QPE (100 mg/L) within $40 \mathrm{~h}$ [25]. Compared to them, YC-XJ1could degrade $96.2 \%$ of QPE (50 mg/L) within 72 h. Pseudomonas sp. DNE-S1 could degrade $90 \%$ of DEP (153 mg/L) within $60 \mathrm{~h}$ [29], Acinetobacter sp. M673 could degrade $80 \%$ of DEP $(0.1 \mathrm{mM} / \mathrm{L})$ within $12 \mathrm{~h}$ [28]. Compared to them, YC-XJ1 could degrade $93 \%$ of DEP $(50 \mathrm{mg} / \mathrm{L})$ within $72 \mathrm{~h}$. Few TPhP degrading bacteria have been reported. Brevibacillus brevis could degrade $92.1 \%$ of TPhP $(3 \mu \mathrm{mol} / \mathrm{L})$ within 5 days [32], Rhodococcus sp. YC-JH2 could degrade $37.36 \%$ of TPhP $(50 \mathrm{mg} / \mathrm{L})$ within 7 days, Sphingopyxis sp. YC-JH3 could efficiently degrade $96.2 \%$ of TPhP (50 mg/L) within 7 days [35]. In my study, YC-XJ1 could degrade $72 \%$ of TPhP $(50 \mathrm{mg} / \mathrm{L})$ within 12 days.

The ANI is one of the most robust measurements of genomic relatedness between bacterial strains, and has a great potential in the taxonomy classification of bacteria as a substitute for the traditional technique. The proposed and generally accepted species boundary for ANI values are 95-96\% [40]. The strain YC-XJ1 was identified as Methylobacterium populi finally.

Due to the great phenotypic plasticity, the Members of the Methylobacterium genus occupy different habitats and distributed in the natural environment widely [41]. They potentially play an important role in mitigating ozone depletion resulting from methyl chloride and methyl bromide emissions [42]. According to the reports, Methylobacterium genus could degrade polycyclic aromatic hydrocarbon [43], 2,2-bis(p-chlorophenyl)-1,1-dichloroethylene [44], 2,4,6-trinitrotoluene, 4-Nitro-2,4-diazabutanal [45], isoprene [46] and other compounds. In this study, it was reported for the first time that Methylobacterium could degrade AOPPs herbicide and OPFRs and PAEs. Aromatic carboxylic acid ester bond and organic phosphoester bond were preferred by strain YC-XJ1.

For atrazine degradation pathway annotated, there was a large percent (10 genes) participate in it. Although atrazine was not detected by previous substrate experiment, it brings up another hint that atrazine, a herbicide different from AOPPs on molecular structure, may be an important substrate of YC-XJ1.

The overall gene functions displayed that the strain YC-XJ1 was a promising candidate for organic degradation. Based on microbial function analysis, the future research would develop an efficient modified engineered bacterium for application.

Environmental factors such as $\mathrm{pH}$ and temperature can affect enzyme activity and stability [47]. The optimal condition of QPEH2 was consistent with the reported characteristics of esterase QpeH [24]. Metal ions also played a key role in the activity of enzymes. Only $\mathrm{Fe}^{2+}$ could serve as activator for QPEH2, different from the previous report that $1 \mathrm{mM} \mathrm{Ca}^{2+}$ and $\mathrm{Cd}^{2+}$ strongly stimulated enzyme activity of QpeH from Pseudomonas sp. J-2 [24].

Among all substrates, quizalofop-p-tefuryl degradation rate was the lowest, and it was also the only AOPPs with tetrahydrofuran ring structure in the side chain of carboxylate. It was speculated that complex side chain and steric hindrance existed to affect the activity of QPEH2.

For the other reported QPE hydrolase, the specific activities of FeH from Rhodococcus ruber JPL-2 were $1.16\left(\mathrm{U} \mathrm{mg}^{-1}\right)$ for QPE with $k_{\text {cat }} / K_{\mathrm{m}}$ value of $3.25 \mathrm{mM}^{-1} \cdot \mathrm{s}^{-1}$ [48]; $4.12 \pm 0.25\left(\mathrm{U} \mathrm{mg}^{-1}\right)$ of $\mathrm{ChbH}$ from Pseudomonas azotoformans QDZ-1, with $k_{\text {cat }} / K_{\mathrm{m}}$ value of $6.57 \mu \mathrm{M}^{-1} \cdot \mathrm{s}^{-1}$ [49]; $7.95 \pm 0.22\left(\mathrm{U} \mathrm{mg}^{-1}\right)$ of FpbH from Aquamicrobium sp. FPB-1, with $k_{\text {cat }} / K_{\mathrm{m}}$ value of $12.85 \mu \mathrm{M}^{-1} \cdot \mathrm{s}^{-1}$ [25]. QPEH2 did not show superior degradation efficiency comparing to them.

According to the identification of metabolites, QPE was converted to QA and ethanol, consistent with the result of QpeH reported [24].

The optimal condition ( $\mathrm{pH} 6.0$ and $35^{\circ} \mathrm{C}$ ) of DEPH1 was different from reported BaCEs04 with optimal condition ( $\mathrm{pH} 7.5$ and $60^{\circ} \mathrm{C}$ ). $\mathrm{Mg}^{2+}$ and $\mathrm{Fe}^{2+}$ could serve as activator for DEPH1, consistent with the characteristics of BaCEs04 [50].

Among all substrates of DEPH1, the degradation rate of DOP was only $10.03 \%$. It was obvious that the enzyme activity decreased with the extension of the side chain of carboxylate.

For the reported dialkyl PAEs hydrolase, the specific activities of BaCEs04 from Bacillus velezensis SYBC $H 47$ towards DEP was $21.27 \pm 1.18\left(\mathrm{U} \mathrm{mg}^{-1}\right)$ [50]; The $k_{\text {cat }} / K_{\mathrm{m}}$ and $K_{\mathrm{m}}$ of dialkyl PAEs hydrolase 
from Camelimonas sp. for DEP was $9.8234 \pm 0.013\left(\mathrm{mM}^{-1} \cdot \mathrm{s}^{-1}\right)$ and $1.5289 \pm 0.021(\mathrm{mM})$ [51]; The $k_{\text {cat }} / K_{\mathrm{m}}$ and $K_{\mathrm{m}}$ of dialkyl PAEs hydrolase from Acinetobacter sp. M673 for DEP was $7.34 \pm 0.34\left(\mu \mathrm{M}^{-1} \cdot \mathrm{s}^{-1}\right)$ and $1.943 \pm 0.012(\mu \mathrm{M})$ [28]. DEPH1 did not show superior degradation efficiency comparing to them.

Although QPEH2 and DEPH1 did not show superior degradation efficiency, more than 40 similar hydrolases genes were screened based on genome annotation, and qpeh 2 and deph1 were only two of them whose activity was verified. The strong degradation activity of YC-XJ1 on the substrate was probably the result of the interaction of multiple hydrolases in vivo, or QPEH2 and DEPH1 were not the hydrolases with the fastest degradation rate. Although a large number of gene functional verification experiments have been carried out, hydrolases of TPhP were still unknow. In order to elaborate the degradation mechanism of TPhP, It was necessary to find the corresponding hydrolase.

Bacteria with the ability to degrade multiple types of organic pollutants have rarely been reported. Methylobacter populi was often isolated in extremely polluted areas and has tolerance to extreme environments. In future, the research would focus on the use of transgenic engineering to transfer QPE and DEP degradation genes from other species into the genome of YC-XJ1 to improve the degradation ability. It was hoped that the Methylobacterium populi YC-XJ1 could be modified as engineered bacteria for practical application in bioremediation of polluted sites.

\section{Materials and Methods}

\subsection{Chemicals and Reagents}

Standards of clodinafop-propargyl, diclofop-methyl, haloxyfop-p-methyl, fluazifop-p-butyl, cyhalofop-butyl, fenoxaprop-p-ethyl, propaquizafop, quizalofop-p-tefuryl, QPE (98.7\% of purity) were purchased from Shenyang Research Institute of Chemical Industry Co., Ltd. (Shenyang, China). QP ( $>95 \%$ of purity), CYP ( $95 \%$ of purity), and quinoxaline (95\% of purity) were purchased from Sigma-Aldrich (St. Louis, MO, USA). Stock solutions $\left(1 \times 10^{4} \mathrm{mg} / \mathrm{L}\right)$ of all standard substance were prepared by dissolving in methanol (HPLC grade).

Standards of DMP, DBP, MEP, DEP, DOP, TPhP, DPP, TDCPP, TCEP, chlorpyrifos, phoxim, benzene, 4-chlorobenzoic acid, phenol, pyrocatechol, salicylic acid, benzoic acid, phthalic acid were also made by dissolving in methanol $\left(1 \times 10^{4} \mathrm{mg} / \mathrm{L}\right)$.

\subsection{Media}

Mineral salts medium (MSM) composed of $1.5 \mathrm{~g} \mathrm{NH}_{4} \mathrm{NO}_{3}, 0.5 \mathrm{~g} \mathrm{KH}_{2} \mathrm{PO}_{4} \cdot 12 \mathrm{H}_{2} \mathrm{O}, 1.5 \mathrm{~g} \mathrm{~K}_{2} \mathrm{HPO}_{4}$, $0.2 \mathrm{~g} \mathrm{MgSO}_{4} \cdot 7 \mathrm{H}_{2} \mathrm{O}, 0.5 \mathrm{~g} \mathrm{NaCl}$ and $1 \%$ o (v/v) trace element solution (TES) in $1.0 \mathrm{~L}$ water. Trace element solution (TES) contained $\mathrm{FeSO}_{4} \cdot 7 \mathrm{H}_{2} \mathrm{O}(2.0 \mathrm{~g} / \mathrm{L}), \mathrm{ZnSO}_{4}(0.1 \mathrm{~g} / \mathrm{L}), \mathrm{CuSO}_{4} \cdot 5 \mathrm{H}_{2} \mathrm{O}(0.03 \mathrm{~g} / \mathrm{L}), \mathrm{MnCl} \cdot 4 \mathrm{H}_{2} \mathrm{O}$ $(0.03 \mathrm{~g} / \mathrm{L}), \mathrm{CoCl} \cdot 7 \mathrm{H}_{2} \mathrm{O}(0.3 \mathrm{~g} / \mathrm{L}), \mathrm{Na}_{2} \mathrm{MoO}_{4} \cdot 2 \mathrm{H}_{2} \mathrm{O}(0.03 \mathrm{~g} / \mathrm{L}), \mathrm{Na}_{2} \mathrm{WO}_{4} \cdot 2 \mathrm{H}_{2} \mathrm{O}(0.02 \mathrm{~g} / \mathrm{L})$. NaCl solution $(200 \mathrm{mg} / \mathrm{mL})$ contained $20 \mathrm{~g} \mathrm{NaCl}$ and $100 \mathrm{~mL}$ PBS $(10 \mathrm{mM})$ buffer. The $\mathrm{pH}$ of all media was adjusted to $7.0 \pm 0.2$, then all media were sterilized at $121^{\circ} \mathrm{C}$ for $20 \mathrm{~min}$.

\subsection{Analytical Methods}

Three biological replications of $10 \mathrm{~mL}$ aqueous samples were extracted with the equal volume of dichloromethane, and $800 \mu \mathrm{L}$ extracts were evaporated in fuming cupboard. The residues were dissolved in $800 \mu \mathrm{L}$ methanol and the solution was filtered through $0.22 \mu \mathrm{m}$ membrane (ANPEL, Shanghai, China) before determined by high performance liquid chromatography (HPLC) system (1200 series, Agilent Technologies Inc., Santa Clara, California, USA) equipped with a C18 column (Agilent Eclipse XDB, $5 \mu \mathrm{m}, 4.6 \times 150 \mathrm{~nm}$ ) and a diode array detector (DAD), see Table S3 for details of the settings.

Three biological replications of $10 \mathrm{~mL}$ aqueous samples were extracted with the equal volume of dichloromethane, and $800 \mu \mathrm{L}$ extracts were evaporated in fuming cupboard. The residues were dissolved in $800 \mu \mathrm{L}$ acetonitrile and the solution was filtered through $0.22 \mu \mathrm{m}$ membrane before detected by gas chromatograph system (GC-2010, SHIMADZU, Kyoto, Japan) equipped with a HP-5 
capillary column (inradium $-0.25 \mathrm{~mm}$, length $-30 \mathrm{~m}$, membrane thickness $-0.25 \mu \mathrm{m}$ ) and a flame ionization detector (FID) [35], see Table S3 for details of the settings.

\subsection{Substrates Utilization Tests}

An inoculum of strain YC-XJ1 was prepared and used to determine the biodegradability of different compounds. $50 \mathrm{mg} / \mathrm{L}$ substrate was set as the initial concentration, i.e., $10 \mathrm{~mL} \mathrm{MSM} \mathrm{(pH} \mathrm{8.0)} \mathrm{containing}$ $50 \mu \mathrm{L}$ stock solutions and $1 \%$ Methylobacterium populi $\mathrm{YC}-\mathrm{XJ} 1$ bacterial suspension $\left(\mathrm{OD}_{600}=0.7\right)$, was incubated at $35{ }^{\circ} \mathrm{C}$ and $180 \mathrm{rpm}$ for 3 days. Each treatment was performed in three replicates, and the samples without inoculation were set as a control. The residual concentration was detected by HPLC or GC as described above (Section 4.3), and standard curves of all substrates were prepared previously, see Figure S12 for details.

\subsection{Genomic DNA Extractions, Library Construction and Sequencing}

The method was used as described in [52].

\subsection{Gene Prediction and Annotation}

The data generated from PacBio and Illumina platform were used for bioinformatics analysis. All of the analyses were performed using I-Sanger Cloud Platform (www.i-sanger.com) from Majorbio Bio-pharm Technology Co., Ltd. (Shanghai, China). The coding sequence (CDS) was predicted with Glimmer v3.02. The tRNA and rRNA were predicted with tRNA-scan-SE v2.0 and Barrnap v0.8. The prophages was predicted using PHAge Search Tool. The gene island (GI) was predicted with Islander v1.2. The predicted CDSs were annotated from the NCBI non-redundant (NR) database, the databases of Swiss-Prot, The Pfam database, Cluster of Orthologous Groups of proteins (COGs), Gene Ontology (GO), Kyoto Encyclopedia of Genes and Genomes (KEGGs), Carbohydrate-Active enzymes (CAZy), Comprehensive Antibiotic Resistance Database (CARD) and Pathogen Host Interactions (PHI) using sequence alignment tools such as BLAST v2.3.0+, Diamond v0.8.35 and HMMER v3.1b2 [52].

\subsection{Average Nucleotide Identity and Alignment Fraction}

The average nucleotide identity (ANI) and alignment fraction (AF) were determined for 8 genomes as shown below using published methods [53,54]. ANI values were calculated for all pairwise comparisons. Custom scripts were used to perform these analyses and generate the ANI dendrogram. Pheatmap3 v 1.0.12 (R packages) was used to visualize the results.

The selected genome sequences were as follows: Methylorubrum populi BJ001, Methylorubrum extorquens CM4, Methylobacterium salsuginis, Methylorubrum rhodinum, Methylobacterium organophilum, Methylobacterium brachiatum TX0642, Methylobacterium aquaticum MA-22A.

\subsection{Collinearity Analysis}

The collinearity analysis was performed using BLASTN v2.80 (E-value cutoff of 10-15) using the Methylorubrum populi YC-XJ1 genome as the query against the Methylorubrum populi BJ001 genome [55]. The visualization was plotted by the SVG (v2.84 https://metacpan.org/release/SVG).

\subsection{Sequence Analysis of qpeh2 and deph1}

Nucleotides and amino acid sequence analysis of the qpeh2 and deph1 were performed using OMIGA 2.0. Blastn and Blastp tools were used for nucleotide and amino acid sequence identity searches, respectively. Phylogenetic tree analysis of the protein sequences was performed using MEGA 5.0 software by neighbor-joining method, Bootstrapping of 1000 replicates and Poisson correction. Homologous sequence alignment with the closest relative hydrolase was performed by ClustalW 
v2.1, and ESPript (v3.0, http://espript.ibcp.fr/ESPript/ESPript/). The presence of a signal peptide was predicted using signaIP $\mathrm{v} 4.0$.

\subsection{Cloning, Expression and Purification of the Recombinant QPEH2 and DEPH1}

The qpeh2 and deph1 genes were PCR-amplified from the genomic DNA of strain YC-XJ1 using the primers containing with BamH I and Hind III sites (Table S4). The PCR products were inserted into the expression vector pET-32a (+) to generate the recombinant plasmid pET-qpeh2 and pET-deph1. The overexpression and purification followed the method described by [56].

\subsection{Biochemical Properties of the Purified Recombinant QPEH2 and DEPH1}

The degradation characteristics of QPEH2 for QPE and DEPH1 for DEP were detected. The optimal reaction $\mathrm{pH}$ was determined by incubating the reaction mixtures at $30{ }^{\circ} \mathrm{C}$ for $10 \mathrm{~min}$ in the following buffers: $10 \mathrm{mM} \mathrm{Na}_{2} \mathrm{HPO}_{4}$-Citric acid buffer, $\mathrm{pH}$ 3.0-7.0; $50 \mathrm{mM}$ Tris- $\mathrm{HCl}$ buffer, $\mathrm{pH}$ 7.0-9.0; and $50 \mathrm{mM}$ Glycine-NaOH buffer, $\mathrm{pH} 9.0-11.0$. The optimal reaction temperature was assessed under $\mathrm{pH} 7.0$ in $10 \mathrm{mM}$ PBS buffer and incubating the reaction mixtures at different temperatures $\left(15-50^{\circ} \mathrm{C}\right)$ for $10 \mathrm{~min}$. The residual concentration was assayed as described above 4.3. Each treatment was performed in three replicates, and the samples without enzyme solution was set as a control.

The effects of potential inhibitors or activators on the enzymatic activity were analyzed by the addition of various metal ion to the reaction mixture in $10 \mathrm{mM}$ PBS buffer ( $\mathrm{pH} 7.0)$, including $\mathrm{Cd}^{2+}$, $\mathrm{Hg}^{2+}, \mathrm{Pb}^{2+}, \mathrm{Zn}^{2+}, \mathrm{Cu}^{2+}, \mathrm{Mn}^{2+}, \mathrm{Ni}^{2+}, \mathrm{Co}^{2+}, \mathrm{Mg}^{2+}, \mathrm{Fe}^{3+}, \mathrm{Fe}^{2+}, \mathrm{Ca}^{2+}(1.0 \mathrm{mM})$. The reaction mixtures were preincubated for $10 \mathrm{~min}$ at $30^{\circ} \mathrm{C}$ with each inhibitor or activator and the residual concentration was assayed as described above 4.3. Each treatment was performed in three replicates, and the samples without any additive was set as a control.

Enzymatic activities towards other substrates were performed in $10 \mathrm{mM}$ PBS buffer (pH 7.0) for $30 \mathrm{~min}$ at $30^{\circ} \mathrm{C}$. The residual substrate concentration was assayed as described above 4.3. Each treatment was performed in three replicates, and the samples without corresponding enzyme was set as a control.

Metabolites of QPE degradation by QPEH2 were identified by HPLC-MS using the method described as [57].

\subsection{Determination of Kinetic Constants}

For kinetic studies, the purified recombinant protein was quantified with the BCA protein assay kit (TIANGEN Biotech Co., Ltd., Beijing, China), and one unit of enzymatic activity was defined as the amount of enzyme required to hydrolyze $1 \mu \mathrm{mol}$ of substrate per minute. $120 \mu \mathrm{g}$ of purified QPEH2 was assayed at varying QPE concentrations $(0.2-2.4 \mathrm{mM})$ under conditions $\left(25^{\circ} \mathrm{C}, \mathrm{pH} 7.0\right)$ in $10 \mathrm{mM}$ PBS buffer. $500 \mu \mathrm{g}$ of purified DEPH1 was assayed at varying DEP concentrations (0.2-2.4 mM) under conditions $\left(25^{\circ} \mathrm{C}\right.$, pH 7.0) in $10 \mathrm{mM}$ PBS buffer. Kinetic parameters $\left(K_{\mathrm{m}}\right.$ and $\left.V_{\max }\right)$ were calculated using a Lineweaver-Burk plot. The specificity constant, $K_{\text {cat }} / K_{\mathrm{m}}$, was calculated to determine the substrate specificity. No more than $10 \%$ of the substrate was hydrolyzed during the assay. Each experiment was carried out in triplicate and samples without enzyme solution were used as a control.

\subsection{Accession Numbers}

The genomic sequences of Methylobacterium populi YC-XJ1 and the nucleotide sequences of qpeh1 gene and qpeh1 gene have been deposited in the GenBank database under accession numbers CP039546, submission ID 2345750 and 2345671, respectively. The strain YC-XJ1 has been deposited in China General Microbiological Culture Collection Center (CGMCC) under accession number CGMCC 18350.

\subsection{Statistical Analysis}

All the statistical analysis was performed by SPSS 13.0 as described in [7]. 


\section{Conclusions}

The strain YC-XJ1 showed great degrading ability towards a wide range of substrate, including AOPPs, OPFRs, PAEs, chlorpyrifos and phoxim. Genome annotation information showed that the strain YC-XJ1 contained a large number of exogenous compounds degradation pathways and hydrolase resources. QPEH2 and DEPH1 were proved to be members of the esterase family V and VII with hydrolysis activity to QPE and DEP. It was hoped that the Methylobacterium populi YC-XJ1 could be modified as engineered bacteria by transgenic engineering technology for practical application in bioremediation of polluted sites.

Supplementary Materials: The following are available online at http://www.mdpi.com/1422-0067/21/12/4436/s1, Table S1: Statistical table of gene function annotation of strain YC-XJ1, Table S2: The information of the protein sequences, Table S3: The detection method details of the substrate, Table S4: The amplification primer of qpeh2 and deph1, Figure S1: The optimal pH of TPhP-degrading by strain YC-XJ1, Figure S2: Phylogenetic trees based on average nucleotide identity (ANI), Figure S3: Collinearity analysis of YC-XJ1 genome and BJ001 genome, Figure S4: Annotation statistics of COG categories of YC-XJ1 genome, Figure S5: Annotation statistics of GO categories of YC-XJ1 genome, Figure S6: Annotation statistics of CAZy database of YC-XJ1 genome, Figure S7: The summary of metabolic pathways of strain YC-XJ1 in KEGG database, Figure S8: Pathway classification of YC-XJ1 genome annotated by KEGG, Figure S9: The sequence alignment of DEPH1 with the most closely related proteins., Figure S10: The phylogenetic analysis of DEPH1, Figure S11: SDS-PAGE analysis of DEPH1 purification, Figure S12: The standard curve of substrate.

Author Contributions: Formal analysis, X.L.; Funding acquisition, Y.Y.; Investigation, X.L.; Methodology, Y.Y.; Project administration, Y.Y.; Writing-original draft, X.L.; Writing-review \& editing, X.L., A.R., J.W. and Y.J. All authors have read and agreed to the published version of the manuscript.

Funding: This work was supported by the National Natural Science Foundation of China [No. 31540067, 21876201] and the Basic Research Fund of Chinese Academy of Agricultural Sciences [No. 1610042017001, 1610042018005 and 1610042018006].

Conflicts of Interest: The authors declare no conflict of interest.

\section{References}

1. Mesnage, R.; Biserni, M.; Wozniak, E.; Xenakis, T.; Mein, C.A.; Antoniou, M.N. Comparison of transcriptome responses to glyphosate, isoxaflutole, quizalofop-p-ethyl and mesotrione in the HepaRG cell line. Toxicol. Rep. 2018, 5, 819-826. [CrossRef] [PubMed]

2. Elefsiniotis, I.S.; Liatsos, G.D.; Stamelakis, D.; Moulakakis, A. Case report: Mixed cholestatic/hepatocellular liver injury induced by the herbicide quizalofop-p-ethyl. Environ. Health Perspect. 2007, 115, 1479-1481. [CrossRef] [PubMed]

3. Zhu, L.Z.; Qi, S.Z.; Cao, F.J.; Mu, X.Y.; Yang, Y.; Wang, C. Quizalofop-P-ethyl exposure increases estrogen axis activity in male and slightly decreases estrogen axis activity in female zebrafish (Danio rerio). Aquatic Toxicol. 2017, 183, 76-84. [CrossRef] [PubMed]

4. Doganlar, Z.B. Quizalofop-p-ethyl-induced phytotoxicity and genotoxicity in Lemna minor and Lemna gibba. J. Environ. Sci. Health 2012, 47, 1631-1643. [CrossRef] [PubMed]

5. Saha, A.; Bhaduri, D.; Pipariya, A.; Jain, N.K. Influence of imazethapyr and quizalofop-p-ethyl application on microbial biomass and enzymatic activity in peanut grown soil. Environ. Sci. Pollut. Res. Int. 2016, 23, 23758-23771. [CrossRef] [PubMed]

6. Gao, D.W.; Wen, Z.D. Phthalate esters in the environment: A critical review of their occurrence, biodegradation, and removal during wastewater treatment processes. Sci. Total Environ. 2016, 541, 986-1001. [CrossRef]

7. Feng, L.; Liu, H.; Cheng, D.; Mao, X.; Wang, Y.; Wu, Z.; Wu, Q. Characterization and Genome Analysis of a Phthalate Esters-Degrading Strain Sphingobium yanoikuyae SHJ. BioMed Res. Int. 2018, 2018, 3917054. [CrossRef] [PubMed]

8. Wang, P.; Wang, S.L.; Fan, C.Q. Atmospheric distribution of particulate- and gas-phase phthalic esters (PAEs) in a Metropolitan City, Nanjing, East China. Chemosphere 2008, 72, 1567-1572. [CrossRef]

9. Teil, M.J.; Blanchard, M.; Chevreuil, M. Atmospheric fate of phthalate esters in an urban area (Paris-France). Sci. Total Environ. 2006, 354, 212-223. [CrossRef]

10. Xie, Z.; Ebinghaus, R.; Temme, C.; Lohmann, R.; Caba, A.; Ruck, W. Occurrence and air-sea exchange of phthalates in the Arctic. Environ. Sci. Technol. 2007, 41, 4555-4560. [CrossRef] 
11. Pereira, C.; Mapuskar, K.; Rao, C.V. Chronic toxicity of diethyl phthalate in male Wistar rats-a dose-response study. Regul. Toxicol. Pharmacol. RTP 2006, 45, 169-177. [CrossRef] [PubMed]

12. Pereira, C.; Rao, C.V. Toxicity study of maternal transfer of polychlorinated biphenyls and diethyl phthalate to 21-day-old male and female weanling pups of Wistar rats. Ecotoxicol. Environ. Saf. 2007, 68, 118-125. [CrossRef]

13. Ghorpade, N.; Mehta, V.; Khare, M.; Sinkar, P.; Krishnan, S.; Rao, C.V. Toxicity study of diethyl phthalate on freshwater fish Cirrhina mrigala. Ecotoxicol. Environ. Saf. 2002, 53, 255-258. [CrossRef]

14. Sonde, V.; D'Souza, A.; Tarapore, R.; Pereira, L.; Khare, M.P.; Sinkar, P.; Krishnan, S.; Rao, C.V. Simultaneous administration of diethylphthalate and ethyl alcohol and its toxicity in male Sprague-Dawley rats. Toxicology 2000, 147, 23-31. [CrossRef]

15. Xu, H.; Shao, X.; Zhang, Z.; Zou, Y.; Chen, Y.; Han, S.; Wang, S.; Wu, X.; Yang, L.; Chen, Z. Effects of di-n-butyl phthalate and diethyl phthalate on acetylcholinesterase activity and neurotoxicity related gene expression in embryonic zebrafish. Bull. Environ. Contam. Toxicol. 2013, 91, 635-639. [CrossRef] [PubMed]

16. Marklund, A.; Andersson, B.; Haglund, P. Screening of organophosphorus compounds and their distribution in various indoor environments. Chemosphere 2003, 53, 1137-1146. [CrossRef]

17. Rodriguez, I.; Calvo, F.; Quintana, J.B.; Rubi, E.; Rodil, R.; Cela, R. Suitability of solid-phase microextraction for the determination of organophosphate flame retardants and plasticizers in water samples. J. Chromatogr. A 2006, 1108, 158-165. [CrossRef]

18. Chen, M.; Jiang, J.; Gan, Z.; Yan, Y.; Ding, S.; Su, S.; Bao, X. Grain size distribution and exposure evaluation of organophosphorus and brominated flame retardants in indoor and outdoor dust and PM10 from Chengdu, China. J. Hazard. Mater. 2019, 365, 280-288. [CrossRef]

19. Lee, S.; Jeong, W.; Kannan, K.; Moon, H.B. Occurrence and exposure assessment of organophosphate flame retardants (OPFRs) through the consumption of drinking water in Korea. Water Res. 2016, 103, 182-188. [CrossRef]

20. Wolschke, H.; Suhring, R.; Xie, Z.; Ebinghaus, R. Organophosphorus flame retardants and plasticizers in the aquatic environment: A case study of the Elbe River, Germany. Environ. Pollut. (Barking, Essex 1987) 2015, 206, 488-493. [CrossRef]

21. Isales, G.M.; Hipszer, R.A.; Raftery, T.D.; Chen, A.; Stapleton, H.M.; Volz, D.C. Triphenyl phosphate-induced developmental toxicity in zebrafish: Potential role of the retinoic acid receptor. Aquat. Toxicol. 2015, 161, 221-230. [CrossRef] [PubMed]

22. Chen, G.; Jin, Y.; Wu, Y.; Liu, L.; Fu, Z. Exposure of male mice to two kinds of organophosphate flame retardants (OPFRs) induced oxidative stress and endocrine disruption. Environ. Toxicol. Pharmacol. 2015, 40, 310-318. [CrossRef] [PubMed]

23. Azubuike, C.C.; Chikere, C.B.; Okpokwasili, G.C. Bioremediation techniques-classification based on site of application: Principles, advantages, limitations and prospects. World J. Microbiol. Biotechnol. 2016, 32, 180. [CrossRef] [PubMed]

24. Zhang, H.; Li, M.; Li, J.; Wang, G.; Liu, Y. Purification and properties of a novel quizalofop-p-ethyl-hydrolyzing esterase involved in quizalofop-p-ethyl degradation by Pseudomonas sp. J-2. Microb. Cell Factories 2017, 16, 80. [CrossRef]

25. Wang, C.; Qiu, J.; Yang, Y.; Zheng, J.; He, J.; Li, S. Identification and characterization of a novel carboxylesterase $(\mathrm{FpbH})$ that hydrolyzes aryloxyphenoxypropionate herbicides. Biotechnol. Lett. 2017, 39, 553-560. [CrossRef] [PubMed]

26. Dong, W.; Jiang, S.; Shi, K.; Wang, F.; Li, S.; Zhou, J.; Huang, F.; Wang, Y.; Zheng, Y.; Hou, Y.; et al. Biodegradation of fenoxaprop-P-ethyl (FE) by Acinetobacter sp. strain DL-2 and cloning of FE hydrolase gene afeH. Bioresour. Technol. 2015, 186, 114-121. [CrossRef]

27. Hou, Y.; Tao, J.; Shen, W.; Liu, J.; Li, J.; Li, Y.; Cao, H.; Cui, Z. Isolation of the fenoxaprop-ethyl (FE)-degrading bacterium Rhodococcus sp. T1, and cloning of FE hydrolase gene feh. FEMS Microbiol. Lett. 2011, 323, 196-203. [CrossRef]

28. Wu, J.; Liao, X.; Yu, F.; Wei, Z.; Yang, L. Cloning of a dibutyl phthalate hydrolase gene from Acinetobacter sp. strain M673 and functional analysis of its expression product in Escherichia coli. Appl. Microbiol. Biotechnol. 2013, 97, 2483-2491. [CrossRef]

29. Fang, H.H.; Liang, D.; Zhang, T. Aerobic degradation of diethyl phthalate by Sphingomonas sp. Bioresour. Technol. 2007, 98, 717-720. [CrossRef] 
30. Jin, L.; Sun, X.; Zhang, X.; Guo, Y.; Shi, H. Co-metabolic biodegradation of DBP by Paenibacillus sp. S-3 and H-2. Curr. Microbiol. 2014, 68, 708-716. [CrossRef]

31. Wu, X.L.; Wang, Y.Y.; Liang, R.X.; Dai, Q.Y.; Chao, W.L. Degradation of di-n-butyl phthalate by newly isolated Ochrobactrum sp. Bull. Environ. Contam. Toxicol. 2010, 85, 235-237. [CrossRef] [PubMed]

32. Wei, K.; Yin, H.; Peng, H.; Lu, G.; Dang, Z. Bioremediation of triphenyl phosphate by Brevibacillus brevis: Degradation characteristics and role of cytochrome P450 monooxygenase. Sci. Total. Environ. 2018, 627, 1389-1395. [CrossRef] [PubMed]

33. Takahashi, S.; Satake, I.; Konuma, I.; Kawashima, K.; Kawasaki, M.; Mori, S.; Morino, J.; Mori, J.; $\mathrm{Xu}, \mathrm{H}$; Abe, K.; et al. Isolation and identification of persistent chlorinated organophosphorus flame retardant-degrading bacteria. Appl. Environ. Microbiol. 2010, 76, 5292-5296. [CrossRef] [PubMed]

34. Kawagoshi, Y.; Nakamura, S.; Nishio, T.; Fukunaga, I. Isolation of aryl-phosphate ester-degrading bacterium from leachate of a sea-based waste disposal site. J. Biosci. Bioeng. 2004, 98, 464-469. [CrossRef]

35. Wang, J.; Khokhar, I.; Ren, C.; Li, X.; Wang, J.; Fan, S.; Jia, Y.; Yan, Y. Characterization and 16S metagenomic analysis of organophosphorus flame retardants degrading consortia. J. Hazard. Mater. 2019, 380, 120881. [CrossRef]

36. Chaudhary, N.; Gonzalez, E.; Chang, S.H.; Geng, F.; Rafii, S.; Altorki, N.K.; McGraw, T.E. Adenovirus Protein E4-ORF1 Activation of PI3 Kinase Reveals Differential Regulation of Downstream Effector Pathways in Adipocytes. Cell Rep. 2016, 17, 3305-3318. [CrossRef]

37. Roth, C.; Weizenmann, N.; Bexten, N.; Saenger, W.; Zimmermann, W. Amylose recognition and ring-size determination of amylomaltase. Sci Adv. 2017, 3, e1601386. [CrossRef]

38. Watanabe, M.; Fukada, H.; Inoue, H.; Ishikawa, K. Crystal structure of an acetylesterase from Talaromyces cellulolyticus and the importance of a disulfide bond near the active site. FEBS Lett. 2015, 589, 1200-1206. [CrossRef]

39. Nakamura, T.; Fahmi, M. Genome-Wide Analysis of Whole Human Glycoside Hydrolases by Data-Driven Analysis in Silico. Int. J. Mol. Sci. 2019, 20, 6290. [CrossRef]

40. Chun, J.; Oren, A.; Ventosa, A.; Christensen, H.; Arahal, D.R.; da Costa, M.S.; Rooney, A.P.; Yi, H.; Xu, X.W.; De Meyer, S.; et al. Proposed minimal standards for the use of genome data for the taxonomy of prokaryotes. Int. J. Syst. Evol. Microbiol. 2018, 68, 461-466. [CrossRef]

41. Dourado, M.N.; Camargo Neves, A.A.; Santos, D.S.; Araujo, W.L. Biotechnological and agronomic potential of endophytic pink-pigmented methylotrophic Methylobacterium spp. BioMed. Res. Int. 2015, 2015, 909016. [CrossRef] [PubMed]

42. McDonald, I.R.; Warner, K.L.; McAnulla, C.; Woodall, C.A.; Oremland, R.S.; Murrell, J.C. A review of bacterial methyl halide degradation: Biochemistry, genetics and molecular ecology. Environ. Microbiol. 2002, 4, 193-203. [CrossRef]

43. Ventorino, V.; Sannino, F.; Piccolo, A.; Cafaro, V.; Carotenuto, R.; Pepe, O. Methylobacterium populi VP2: Plant growth-promoting bacterium isolated from a highly polluted environment for polycyclic aromatic hydrocarbon (PAH) biodegradation. Sci. World J. 2014, 2014, 931793. [CrossRef] [PubMed]

44. Eevers, N.; Van Hamme, J.D.; Bottos, E.M.; Weyens, N.; Vangronsveld, J. Draft Genome Sequence of Methylobacterium radiotolerans, a DDE-Degrading and Plant Growth-Promoting Strain Isolated from Cucurbita pepo. Genome Announc. 2015, 3, e00488-15. [CrossRef] [PubMed]

45. Fournier, D.; Trott, S.; Hawari, J.; Spain, J. Metabolism of the aliphatic nitramine 4-nitro-2,4-diazabutanal by Methylobacterium sp. strain JS178. Appl. Environ. Microbiol. 2005, 71, 4199-4202. [CrossRef]

46. Srivastva, N.; Vishwakarma, P.; Bhardwaj, Y.; Singh, A.; Manjunath, K.; Dubey, S.K. Kinetic and molecular analyses reveal isoprene degradation potential of Methylobacterium sp. Bioresour. Technol. 2017, 242, 87-91. [CrossRef]

47. Zhao, B.; Hua, X.; Wang, F.; Dong, W.; Li, Z.; Yang, Y.; Cui, Z.; Wang, M. Biodegradation of propyzamide by Comamonas testosteroni $\mathrm{W} 1$ and cloning of the propyzamide hydrolase gene camH. Bioresour. Technol. 2015, 179, 144-149. [CrossRef]

48. Liu, H.M.; Lou, X.; Ge, Z.J. Isolation of an aryloxyphenoxy propanoate (AOPP) herbicide-degrading strain Rhodococcus ruber JPL-2 and the cloning of a novel carboxylesterase gene (feh). Braz. J. Microbiol. 2015, 46, 425-432. [CrossRef] 
49. Nie, Z.J.; Hang, B.J.; Cai, S.; Xie, X.T.; He, J.; Li, S.P. Degradation of cyhalofop-butyl (CyB) by Pseudomonas azotoformans strain QDZ-1 and cloning of a novel gene encoding CyB-hydrolyzing esterase. J. Agric. Food Chem. 2011, 59, 6040-6046. [CrossRef]

50. Huang, L.; Meng, D.; Tian, Q.; Yang, S.; Deng, H.; Guan, Z.; Cai, Y.; Liao, X. Characterization of a novel carboxylesterase from Bacillus velezensis SYBC H47 and its application in degradation of phthalate esters. J. Biosci. Bioeng. 2020, 129, 588-594. [CrossRef]

51. Chen, X.; Zhang, X.; Yang, Y.; Yue, D.; Xiao, L.; Yang, L. Biodegradation of an endocrine-disrupting chemical di-n-butyl phthalate by newly isolated Camelimonas sp. and enzymatic properties of its hydrolase. Biodegradation 2015, 26, 171-182. [CrossRef] [PubMed]

52. Cai, L.; Zheng, S.W.; Shen, Y.J.; Zheng, G.D.; Liu, H.T.; Wu, Z.Y. Complete genome sequence provides insights into the biodrying-related microbial function of Bacillus thermoamylovorans isolated from sewage sludge biodrying material. Bioresour. Technol. 2018, 260, 141-149. [CrossRef] [PubMed]

53. Goris, J.; Konstantinidis, K.T.; Klappenbach, J.A.; Coenye, T.; Vandamme, P.; Tiedje, J.M. DNA-DNA hybridization values and their relationship to whole-genome sequence similarities. Int. J. Syst. Evol. Microbiol. 2007, 57 Pt 1, 81-91. [CrossRef]

54. Varghese, N.J.; Mukherjee, S.; Ivanova, N.; Konstantinidis, K.T.; Mavrommatis, K.; Kyrpides, N.C.; Pati, A. Microbial species delineation using whole genome sequences. Nucleic Acids Res. 2015, 43, 6761-6771. [CrossRef]

55. Altschul, S.F.; Gish, W.; Miller, W.; Meyers, E.W.; Lipman, D.J. Basic local alignment search tool. J. Mol. Biol. 1990, 215, 403-410. [CrossRef]

56. Jia, Y.; Wang, J.; Ren, C.; Nahurira, R.; Khokhar, I.; Wang, J.; Fan, S.; Yan, Y. Identification and characterization of a meta-cleavage product hydrolase involved in biphenyl degradation from Arthrobacter sp. YC-RL1. Appl. Microbiol. Biotechnol. 2019, 103, 6825-6836. [CrossRef]

57. Ren, L.; Jia, Y.; Zhang, R.; Lin, Z.; Zhen, Z.; Hu, H.; Yan, Y. Insight into Metabolic Versatility of an Aromatic Compounds-Degrading Arthrobacter sp. YC-RL1. Front. Microbiol. 2018, 9, 2438. [CrossRef]

(C) 2020 by the authors. Licensee MDPI, Basel, Switzerland. This article is an open access article distributed under the terms and conditions of the Creative Commons Attribution (CC BY) license (http://creativecommons.org/licenses/by/4.0/). 